\title{
Leitura como resistência: Ernesto Penteado e José Nogueira leitores de Nietzsche
}

\author{
Reading as resistance: Ernesto Penteado and José Nogueira readers of Nietzsche
}

\author{
Antonio Vinicius Lomeu \\ Doutorando em História pela Universidade Nacional de La Plata \\ antoniolomeu@hotmail.com
}

\begin{abstract}
Resumo: O presente artigo pretende refletir sobre a leitura como uma forma de resistência, tomando como exemplo a maneira através da qual o major brasileiro José Nogueira e o jornalista Ernesto Penteado recepcionaram os textos do filósofo Friedrich Nietzsche (18441900). Para tanto partiremos, sobretudo, das proposições de Michel De Certeau, que consideram a leitura como um ato de resistência, em distintos níveis, contra a dominação que a própria mensagem do texto representa. Essas reflexões têm como objetivo entender a circulação das ideias do filósofo alemão no Brasil e a prática de uma história intelectual a partir de um novo ângulo.
\end{abstract}

Palavras-chave: Nietzsche; Leitura; Historia Intelectual; Microresistência.
Abstract: This article aims to reflect on reading as a form of resistance, taking as an example the way in which the Brazilian major José Nogueira and journalist Ernesto Penteado received the texts of the philosopher Friedrich Nietzsche (1844-1900). To do so, we will start from the propositions of Michel De Certeau and others, who consider reading as an act of resistance, at different levels, against the domination that the text message itself represents. These reflections aim to understand the circulation of the German philosopher's ideas in Brazil and the practice of an intellectual history from a new angle.

Keywords: Nietzsche; Reading; Intellectual History;

Microresistence. 
Leitura e resistência, em princípio, parecem ser dois termos que não possuem relação entre si. O primeiro se refere a uma pratica silenciosa, oculta, que quase não deixa rastros e não carrega uma relação conflituosa com seu entorno. O segundo estaria vinculado a uma forma de uma reação a um determinado tipo de dominação, isto é, possui uma carga de tensão e tende a expressar uma luta que se dá em um determinado contexto.

No entanto, podemos encarar o ato de leitura como um ato de resistência na medida em que ler é consumir ativamente, assimilar e conferir outro sentido ao texto lido, distinto do propósito inicial do autor. Nesse sentido, tal como nos propõe Michel De Certeau em seu celebre texto "Ler: uma caça furtiva", o ato de ler pode ser considerado uma atividade criadora, de consumo ativo, que não se resume à ideologia "consumo- receptáculo" e à ideia de um processo passivo-harmonioso, mas sim indica um ato de resistir.

Nesse sentido, o presente artigo pretende refletir sobre a leitura como uma forma de resistência, tomando como exemplo a maneira através da qual o major brasileiro José Nogueira e o jornalista Ernesto Penteado se apropriaram dos textos do filósofo Friedrich Nietzsche (1844-1900), aprofundando-se sobretudo nas proposições de De Certeau e de outros autores que vão na mesma direção como Roland Barthes e Roger Chartier. Ao compreender a leitura como um processo criativo, no qual o leitor é um peregrino num sistema imposto (texto) e possui um papel ativo nessa peregrinação, desejamos aproximá-la ao ato de resistência, cujas táticas próprias, mais ou menos conscientes, modificam seu objeto e inventam nos textos algo distinto do que era sua intenção.

Em linhas gerais, buscaremos considerar, portanto, a leitura como um ato de resistência contra a dominação que a própria mensagem do texto representa. Para tanto, analisaremos as leituras efetuadas por Penteado e Nogueira de Nietzsche cujos indícios podem ser notados em artigos publicados nos periódicos A Razão (1909) e Jornal Pequeno (1911). A escolha desses dois leitores se deu em função de suas posições sociais de "homens comuns", ou seja, não faziam parte dos círculos intelectuais hegemônicos no Brasil nesse momento. ${ }^{1}$ Além disso, ambos escreviam para dois jornais populares pequenos e de pouca circulação diária. A partir dessas seleções, queremos

\footnotetext{
${ }^{1}$ A noção de "homens comuns" se ancora nas reflexões de De Certeau.
} 
captar um tipo de leitura popular de Nietzsche, que se deu fora do âmbito intelectual consagrado. ${ }^{2}$

Nossa discussão girará em torno das seguintes questões: como um autor alemão foi lido em Sergipe e Pernambuco, dois locais distante do centro hegemônico de produção intelectual brasileiro? De que maneira essas leituras podem ser entendidas como leituras resistentes? Essas reflexões têm como objetivo entender a circulação das ideias do filósofo alemão no Brasil e a prática de uma história intelectual a partir de um novo ângulo.

\section{Introdução}

O presente artigo foi produzido como requisito necessário para a aprovação do seminário de doutorado "Microresistencia e infrapolítica. Debates actuales sobre resistencia cotidiana de los dominados" ministrado pelo professor Dr. Julian Carrera em 2019, sendo apresentado como trabalho final do curso. O seminário teve como objetivo principal discutir as novas contribuições teóricas em torno dos conceitos de resistência cotidiana, microresistencia e infrapolitica. Para tanto, nos concentramos na analise de tipos particulares de resistência ao poder hegemônico protagonizada por indivíduos que sofrem algum tipo de dominação, a partir dos estudos de James Scott e Michel De Certeau - duas das principais referências no tema - e dos questionamentos decorrentes das propostas desses autores. Apesar de ambos se deterem no estudo das mais diversas formas de resistências cotidianas aos tipos de dominação, há uma divergência fundamental entre as duas propostas. Enquanto que James Scott se interessa pela consciência dos atos de resistência, propondo a noção de discursos ocultos como condutas fora de cena e a noção de disfarce como uma camuflagem de dissidências, Michel De Certeau argumenta que o ato em si mesmo é o mais importante e não suas intenções, concentrando-se nas diversas praticas dos dominados e observando as brechas que o sistema deixa e que são aproveitadas pelos subordinados (CARRERA, 2019: 2-3). O historiador francês, no entanto, se interessa pelas praticas do homem comum, isto é, por uma serie de atividades de natureza subterrânea, que são efêmeras, frágeis e circunstanciais. Essas praticas criativas são caracterizadas pelo uso de um

\footnotetext{
2 Esse caráter de "homens comuns" dos dois leitores deve ser relativizado, pois Ernesto Penteado foi jornalista e José Nogueira foi militar, isto é, gozavam de certa posição privilegiada na estrutura social. No entanto, a nível nacional, foram duas figuras que não se destacaram no âmbito intelectual, sendo pouquíssimos estudados pela historiografia. Além disso, são escassos os registros de suas trajetórias individuais.
} 
produto de diferentes formas, ou seja, pode ser considerada uma atividade de consumo e de ressignificação.

Adiante, tentaremos entender de que maneira o ato de ler pode ser considerado um ato de resistência através do processo que ressignifica ou rejeita o que foi lido e como essas ponderações podem contribuir para a história intelectual. Da mesma forma, buscaremos analisar porque uma pratica tão banal e cotidiana pode se constituir como um modo de resistir. Para tanto, primeiro faz-se necessário examinar como De Certeau entende o cotidiano, seu conceito de reapropriação e suas noções de da resistência.

\section{O leitor como protagonista: leitura como resistência e apropriação}

Em 1967, Roland Barthes, em seu artigo “A morte do autor”, propõe o entendimento de um texto como um intertexto que nenhum autor pode controlar, pois cada significado alude a uma multiplicidade sem limite de sentidos desprovida de centro e origem. O intelectual francês realiza uma crítica à visão de que o texto é um espaço que faz referência um ou mais sentidos específicos e é dotado de uma pluralidade controlada de significados. A partir dessa nova perspectiva revela-se uma ética que indica uma prática de leitura que respeite a pluralidade do texto. De acordo com Barthes:

[...] um texto não é feito de uma linha de palavras, libertando um sentido único, de certo modo teológico (que seria a «mensagem»do Autor-Deus), mas um espaço de dimensões múltiplas, onde se casam e se contestam escritas variadas, nenhuma das quais é original: o texto é um tecido de citações, saldas dos mil focos da cultura (BARTHES, 2004: 3).

Mais tarde, Barthes apontou à ideia de que um texto resiste à domesticação reduz o poder de quem o escreve, assumindo o controle sobre ele. Portanto, devido à morte do autor, haveria, o "nascimento do leitor". A contundência dessa nova proposta é proposital na medida em que há um esforço de pôr fim à tirania do autor, um desejo de libertação obtido através de uma concepção de intertextualidade aberta e de um leitor que se opõe à obra e aos leitores tradicionais (BELLEI, 2014: 164). Para Barthes, a crítica clássica preocupada com aquele que escreve, nunca se ocupou do leitor, figura na qual estão reunidas escritas múltiplas, saídas de várias culturas e que entram umas com as outras em diálogo em paródia, em contestação. 
Em diálogo com Barthes e outros teóricos, De Certeau afirma que o homem comum e suas práticas cotidianas, entre elas a leitura, têm sido ignorados pelas Ciências Sociais, de uma maneira geral, como objetos de análise. A partir desse diagnostico, em seu ensaio "A invenção do cotidiano" há uma tentativa de entender essas práticas ocultas dos heróis anônimos, personagens dispersos praticamente inexistentes nos livros de história. Nesse texto, através de uma grande influencia do pensamento de Henri Lefebvre, o cotidiano ganha um papel de destaque, rompendo com a tendência do discurso cientificista, incorporado pelas ciências humanas, que atribuía um sentido humilde e uma aparência insignificante a esse nível de experiência. Com isso, o cotidiano dos homens comuns perde seu caráter alienado e rotineiro e se torna uma verdadeira via de transformação das praticas, guiada por um interesse emancipador. Ao cotidiano, portanto, é atribuído um caráter politizado carregado de conflitos e tensões, pois é abordado desde uma perspectiva que complexifica a dominação. Essa visão se afasta da ideia de uma cotidianidade cuja principal característica seria a internalização de uma ordem, ou seja, de uma postura passiva diante dos conflitos.

Desse modo, o historiador francês chama atenção para os limites da ordem e da disciplina, destacando a incompletude de qualquer estratégia de dominação e deslocando o foco da reprodução do existente para a potencialidade de transformação do existente. Nessa perspectiva, as práticas cotidianas se apresentam como formas de resistência, pois revelam uma serie de "maneiras de fazer" criativas que também são furtivas, esquivas, imprecisas, silenciosas, fragmentadas e artesanais. Essas maneiras de fazer que fabricam são uma produção dominada oculta, dispersa e discreta, distinta da produção dominante ruidosa, centralizada e espetacular. A primeira tem como resultados produtos próprios; a segunda, por outro lado, consiste na maneira de empregar os produtos impostos pela ordem econômica vigente. Dentre essas praticas ou maneiras de fazer do cotidiano, quase invisíveis e silenciosas, encontra-se a leitura, tendo em vista que ela denota um uso ou consumo cultural, ou seja, uma forma de fabricar aquilo que recebe. Segundo De Certeau a leitura é uma pratica cotidiana que "produz sem capitalizar, sem dominar o tempo (2000: LI)" e que "apresenta todas as características de uma produção silenciosa (2000: LII)". Em contraposição a ideia de que a leitura seria o ponto máximo da passividade, que caracteriza o consumidor visto como um mero espectador em uma sociedade do espetáculo, o historiador francês propõe a seguinte definição: "Na verdade, a atividade leitora apresenta ao contrario todas as características de uma produção silenciosa: deriva através da página, 
metamorfose do texto por meio do olho viajante, improvisação e expectação de significações induzidas com algumas palavras, encavalgamentos de espaços escritos, dança efêmera" (DE CERTEAU, 2000: LII).

Ademais, de acordo com De Certeau o leitor sofre com a ação do tempo, se esquece ao ler, esquece o que foi lido, não consegue armazenar o texto, exceto quando o escreve ou "grava" em sua memória. Em função disso, segundo o autor, na atividade leitora há uma produção que também é uma invenção, isto é uma reapropriação do texto que permite o leitor habita-lo como um apartamento alugado, transformando-o em seu momentaneamente.

Enquanto as escrituras de textos, que funcionam como estratégias dos dominados, são capazes de produzir, quadricular e impor; as maneiras de ler, empregadas como táticas dos dominados, podem somente utilizá-los, manipulá-los ou desviá-los. De acordo com De Certeau:

Mas inepto para armazenamento (exceto quando ele escreve ou "grava" [em seu memorial) o leitor não se protege contra a deterioração do tempo (esquece de ler e esquece o que foi lido) a não ser quando adquire o objeto (livro, imagem) que é apenas o sucessor (o vestígio ou a promessa) de momentos "perdidos" ao ler . Insinua os truques do prazer e da reapropriação no texto do outro: caça furtiva, transporta-se, torna-se plural como os ruídos dos corpos. Perspicaz, metáfora, combinatória, essa produção também é uma "invenção" da memória (DE CERTEAU, 2000: LII).

As diversas praticas de leitura - operações multiformes, fragmentadas, desprovidas de ideologias e instituições próprias - são práticas do tipo tático, já que revelam a engenhosidade do mais fraco e astucias de outros interesses que não estão determinados nem captados pelos sistemas onde são desenvolvidos. No caso da leitura, especificamente, o leitor se apropria do texto, inventando um mundo diferente que já não é o do autor e sim do leitor. A leitura, por conseguinte, não possui um caráter passivo, pois representa um ato de consumo, uma forma particular de usar um produto (texto), e possui uma variedade de métodos.

Em consonância com De Certeau, o também historiador Roger Chartier, em sua obra História Cultural: entre práticas e representações nos oferece o conceito de apropriação como uma forma de se investigar a história do ato de ler como invenção 
criadora (CHARTIER, 2002: 136). Segundo Chartier, é necessário examinar os "processos pelos quais, em face de um texto, é historicamente produzido um sentido e diferenciadamente construída uma significação (CHARTIER, 2001: 13)". Por conseguinte, Chartier deseja questionar a perspectiva que considera os textos e as palavras como algo "radicalmente aculturante", na medida em que pretendem moldar os pensamentos e as condutas. Contra essa perspectiva, que encontra sua síntese máxima na noção de influência, largamente empregada na história das ideias, privilegiaremos o conceito de apropriação, pois desejamos mostrar um caráter criativo e inventivo dos leitores diante da obra do filósofo alemão, sem desembocar, com isso, na ingenuidade de se pensar em uma total liberdade da leitura. Segundo Chartier:

Contra uma visão simplista que supõe a servidão dos leitores quanto às mensagens inculcadas lembra-se que recepção é criação, e o consumo, produção. No entanto, contra a perspectiva que postula a absoluta liberdade dos indivíduos e a força de uma imaginação sem limites, lembra-se que toda criação está encerrada nas condições de possibilidade historicamente variáveis e socialmente desiguais (CHARTIER, 2001: 13).

Para Chartier a noção de apropriação nos ajuda a pensar os processos de recepção a partir da ideia da leitura como invenção criadora, ou seja, o ato de leitura não é anulado no próprio texto, ele é dotado de liberdade, mesmo que esse leitor seja pensado pelo autor, pelo comentador e pelo editor como devendo ficar sujeito a um sentido único, a uma compreensão correta, e a uma leitura autorizada. ${ }^{3}$ Por conseguinte, essa liberdade não é tampouco total, pois cada leitor está preso às suas condições de leitura, ou seja, às instituições, a um grupo na sociedade e, sobretudo, ao seu tempo histórico, fatores que condicionam sua leitura.

Partindo do novo campo de possibilidades aberto pelas propostas dos autores franceses supracitados, a seguir, analisaremos a recepção de Ernesto Penteado e José

\footnotetext{
${ }^{3}$ É importante ressaltar que Nietzsche foi, ele mesmo, um grande defensor do perspectivismo, e sempre se posicionou contra aqueles que viam em seu pensamento algo de doutrinário. A leitura, para Nietzsche, deveria promover, antes de tudo, a transformação do indivíduo naquilo que ele é. Nesse sentido, podemos perceber no próprio pensamento do filósofo uma preocupação com a criatividade e a independência do leitor, ou seja, que o leitor, tendo vivenciado e digerido o que leu, possa produzir algo próprio a partir do texto lido. Mesmo assim, uma grande quantidade de comentadores de Nietzsche direciona sua leitura para uma determinada forma de se ler, autorizada ou mais coerente, ou tentam desfazer os "mal-entendidos" da sua obra.
} 
Nogueira de Nietzsche. Analisaremos seus textos e em que contexto da discussão por eles apresentadas aparece o filósofo.

\section{A leitura de José Nogueira}

Durante os anos de 1900 a 1910, o major José Nogueira, natural de Estância cidade do interior de Sergipe, foi gerente e redator do jornal A Razão, que era editado na mesma cidade. De acordo com Ana Barbosa Santos, “o título do jornal alinhou-se ao ideário vigente no país durante o final do século XIX e início do XX, coadunando-se com o pensamento positivista, de valorização da ciência, da civilização e da modernidade (2017: 66)”. Apesar disso, nas páginas do jornal podemos encontrar artigos e notícias sobre assuntos diversos, desde os mais cultos até os mais populares, assim como inúmeras reflexões religiosas de cunho católico. No entanto, reflexões mais filosóficas referentes ao Direito, a Justiça, o Progresso Nacional eram constantes em suas edições. Após a saída do A Razão, Nogueira começa a escrever para o periódico Estado de Sergipe, em Aracaju, onde também começa a trabalhar como suplente da subdelegacia de polícia do $1^{\circ}$ distrito da Capital (A RAZÃO, 1910: 2).

No dia 9 de maio de 1909, o militar publicou um artigo de sua autoria, na primeira página do jornal, no qual cita Nietzsche. O texto, intitulado "Aparando Golpes", trata-se de uma resposta a uma suposta agressão de um escritor da Folha de Sergipe cujo nome, Palmeira do Monte, é citado pelo autor. Como epígrafe, encontramos um provérbio exaltando a paciência e a glória de passar por cima das injúrias feita pelo homem. Nos primeiros parágrafos podemos identificar a indignação do militar diante do ataque de Palmeira do Monte, considerado por ele como "fuzilaria dos doestos (aqueles que insultam)" que se negam a combater em "campo descoberto e raso" e "não abrem mão do sistema de guerrilhas por emboscada, o qual se tem vantagens não deixa de ser ilegal e desairoso (NOGUEIRA, 1909: 1)”.

Classificados como sofistas e pseudografos, os agressores também são taxados de grosseiros, vaidosos e pedantes. Defendendo os escritores do periódico A Razão, Nogueira afirma: "nós não afetamos coisa alguma, nem andamos fazer alarde de nossos "vários conhecimentos filosóficos porque muito pouco sabemos e disto estamos convencidos. Pedantismo talvez haja por lá e muito.” Para o major, Sergipe não está “cheio de poetas, jornalistas e sábios (Grifo de Nogueira)" como seu detrator diz, pois “nenhum de seus colegas será capaz de se considerar como tal”. Outra acusação de seu 
adversário é a de que Nogueira seria um admirador do criminalista Ferri. Isso parece irrita-lo bastante, já que o responde do seguinte modo: "não sofremos da mania dos 'nomes próprios'... pela tua descoberta de ser 'Ferri o maior criminologista que se conhece', etc, etc, damos-te um doce, podes mandar procurá-lo." E continua: "Prova como somos ferristas pois só assim ficamos convencidos. Admiramos Ferri como admiramos muitos outros homens ilustres nacionais e estrangeiros." Para o militar “Admirar não é fazer profissão de fé."

No parágrafo seguinte, demonstrando profunda indignação, Nogueira chama seu adversário de "Polycocephalo (um protista, uma ameba)" por ter entendido mal a discussão apresentada no artigo “A ordem social” de Eugênio M. de Hostos publicada no periódico, um ano antes. Segundo o militar, a definição de Hostos, transcrita no jornal teria que ver com o Socialismo, e se defende dizendo "não penses que confundimos as coisas". A partir desse ponto é apresentada sua concepção de Socialismo e uma apologia a esse sistema. De acordo com Nogueira, "Pelo estudo da Sociologia com a História chegamos ao Socialismo sem grande esforço. Foi o que quisemos dizer. O socialismo será praticável em tempo mais ou menos próximo.” Sendo assim, o socialismo alcançaria o triunfo completo, "à medida que o egoísmo for se atenuando no coração do homem e os costumes se suavizando".

No bojo dessa discussão, sobre a consolidação do Socialismo, surge a citação à Nietzsche. Antes dela, no entanto, há uma forte crítica ao Individualismo, através da exaltação do Socialismo e ataques a Palmeira do Monte. Para Nogueira, "A força do Socialismo existe em si mesmo" e seu adversário, um "homem nascido e educado, desenvolvido no meio quente e no bem-estar, do luxo" condena o Socialismo por não ter condições "de duvidar da legitimidade da situação que frui [...] julgando que uns nasceram para reis outros para escravos". Dessa maneira, o militar afirma que "absurdo é o Individualismo" alegando que seu crítico, individualista, teria se esquecido da "religião que professa e serve muito dignamente" cujo mandamento abdica "amar ao próximo como a ti mesmo". Com isso, Nogueira marca a diferença entre a filosofia individualista que professa o seu crítico e a de Cristo, a qual deveria seguir de maneira coerente, em função de sua posição social. Nesse contexto, o filósofo alemão é mencionado:

Os individualistas como Tucker, Stirner e Nietzsche e outros são exceção aberta no seio da humanidade por causa hoje conhecidas e até classificáveis. 
Nietzsche levou o egoísmo ao extremo ao criar os superhomens, ideia que tem desvairado muita gente de temperamento impulsivo, orgulhoso e brusco. Não há menino bonito por aí que tenha lido o citado escriptor que não se deixe impressionar, que, por qualquer dá cá aquela palha não se perfile e arrogante diga: sou superior a tudo e a todos, sou um superhomem! (NOGUEIRA, 1909: 2)

Após esse trecho, o militar decreta: "O Individualismo, tome a feição que tomar, mascare-se com os rótulos mais pomposos, em síntese é isto: o egoísmo grosseiro e primitivo do homem a tentar se estabelecer no seio da sociedade moderna". Na conclusão do artigo, Nogueira afirma que, embora seu detrator tenha impensadamente alegado contra a dignidade de seu jornal, não se intimida com seus ataques.

\section{A leitura de Ernesto Penteado}

Natural do estado de São Paulo, Ernesto Penteado atuou primeiro como jornalista em sua terra natal e depois como colaborador do Jornal Pequeno, um periódico pernambucano de circulação local. Em sua primeira edição no dia $1^{\circ}$ dia julho de 1898, em nota editorial, o Pequeno Jornal, como se chamava nesse momento, exalta a republicana federativa, a constituição democrática e os direitos individuais. Ademais, declara que

visa doutrinar o povo em todos os ensinamentos do espírito moderno: despertar-lhes os nobres estímulos para a iniciativa particular; provocar-lhe as energias para o fortalecimento da solidariedade dos interesses; reanimarlhe as forças para resistência ao ataque e ao esbulho dos seus direitos; servir de intérprete de suas necessidades, de suas queixas e de suas justas indignações aos dominantes do dia (PEQUENO JORNAL, 1898: 1).

Apesar do periódico seguir essa orientação em artigos publicados nas edições posteriores, podemos encontrar também seções humorísticas, notícias locais, divulgação de eventos religiosos católicos, propagandas de produtos de consumo diário, anúncios de emprego etc. Logo em sua estreia no jornal, em 11 de agosto de 1911, Penteado cita diretamente Nietzsche, na primeira página, em um artigo intitulado "A Lógica dos Homens" que, de maneira resumida, reflete sobre a diferença entre as leis naturais e as 
leis dos homens. ${ }^{4}$ Segundo o escritor paulista, a natureza "segue seu caminho sem ouvir “nossos aplausos e nossos protestos (PÈNTEADO, 1911: 1)" e possui sua própria lógica, a qual poucos homens conseguem entender. Os raros indivíduos que alcançam a compreensão da lógica natural, de acordo com o Penteado, a revestem de "formas obscuras, com toda vaidade de mostrar erudição..." sendo, por isso, "inimigos da simplicidade (PÈNTEADO, 1911: 1)”. Aquele que logra conservar seu espírito ao abrigo das algemas duma escola, seria o verdadeiro sábio, pois seu poder de observação não estaria submetido a nenhum sistema, por melhor arquitetado que esteja.

Penteado afirma que as pesquisas sobre o mundo dos fenômenos têm se deparado com grandes e, às vezes, insuperáveis obstáculos em função da falsa educação que deram nossos pais e preceptores, responsáveis por incutir-nos hábitos contrários a uma sã disciplina intelectual. Por conseguinte, nós seriamos facilmente sugestionados por doutrinas cujos falsos fulgores são mais fabricados pelo coração que pela inteligência. Segundo o autor, de maneira sarcástica, essas doutrinas costumam "usurpar o nome da ciência", pois sempre apresentam uma nova concepção do homem e das coisas, proclamando a verdade toda.

Classificadas de maneira irônica como "arrazoados" (coerentes, lógicos), doutrinas como a sociologia, a história, a moral dos teólogos e metafísicos não mereceriam o nome de ciências, pois ainda não foi achada a solução de seus problemas capitais. Apesar de estarem despojadas de suas vestes infantis, essas disciplinas não possuem o "rigor que vemos nas ciências exatas (PÈNTEADO, 1911: 1)".

Segundo o autor, os sentimentos sempre desempenham um papel importante na expansão de suas faculdades e de seu trabalho mental, embora a sua ação nem sempre seja percebida. É nesse contexto que Penteado retorna ao assunto principal do artigo citando o filósofo alemão:

Mas voltemos à lógica dos homens.

Suponhamos a seguinte tese de Nietzsche: os fracos não têm direito à vida.

\footnotetext{
${ }^{4}$ Na edição analisada, o artigo que menciona Nietzsche vem seguido de uma propaganda de refrigerante Bilz e de conhaque Dupuy em francês. Na mesma página encontram-se uma seção humorística, notícias e informações sobre eventos religiosos na cidade de Recife além de outras propagandas de bebidas. É interessante chamar atenção para o contexto da parte do jornal no qual foi publicado pois reforça ainda mais sua utilização popular em meio a produtos de utilização cotidiana.
} 
Qual homem, de sentimentos nobremente altruísticos, é capaz de abraçar, com entusiasmo, a sentença de morte formulada pelo grande e original pensador? Quem ousaria eliminar da cena da vida um pobre octagenário que lhe viesse a suplicar um pedaço de pão para mitigarlhe a fome? Os próprios monstros se recusam a tanta crueldade (PÈNTEADO, 1911: 1).

$\mathrm{O}$ autor continua seu artigo afirmando que aquilo que nem um perverso se atreveria a fazer, a natureza sim o faria, no entanto, servindo-se de processo menos violentos. Surda aos gemidos dos que sofrem, a natureza comete atrocidades contra os homens, reserva carinhos justamente para quem deles menos precisa e desconhece o sentimento de caridade tão enaltecido pelas almas amorosas. Segundo Penteado, embora haja uma tendência de a razão substituir a força, a primeira, porém, também é "uma das infinitas modalidades" da segunda.

Ao longo do artigo, há um esforço para se estabelecer uma comparação entre as leis dos homens e da natureza e uma tentativa de definir a diferença entre elas. De acordo com o autor, "a lógica dos homens seria a mesma da natureza se ele (o homem) pudesse agir sem a interferência do mais ardiloso dos inimigos - o seu próprio coração". Ao confundir a voz do coração com a voz da inteligência, o homem sofre constantes derrotas e "quando ambos se põem a falar, vence quem mais grita e quem mais grita é o coração." Consequentemente, o homem experimenta um estado natural de alucinação causador de ações incongruentes e incoerentes.

Para concluir, o jornalista afirma que "é tão grande a influência que o coração tem sobre a inteligência que, não raro, chegamos a ter a percepção de um cavalo e persistimos em asseverar que o que vimos foi um bezerro", por isso faz o seguinte apelo: "desconfiemos de nós mesmos enquanto não acharmos fortemente seguros contra os ardis do coração" argumentando que "as leis da natureza jamais podem invalidar as leis que dirigem a inteligência", uma vez que o coração gosta de assumir o comando só para ter o prazer de nos aborrecer.

\section{As recepções de Nietzsche}

Tanto o militar sergipano como o jornalista paulista apresentaram distintas formas de recepcionar Nietzsche. Penteado, embora não faça referência formal, menciona o trecho de Anticristo "os fracos não têm direito à vida." que se aproxima do 
trecho original "Os fracos e malogrados devem perecer: primeiro princípio de nossa filantropia." (NIETZSCHE, 2007: 12). Por outro lado, Nogueira não cita nenhum trecho de sua obra embora tenha demonstrado um conhecimento geral sobre seu pensamento e até sobre sua recepção. Leitores diretos ou não, esses escritores demonstraram leituras resistentes aos textos nietzschianos. Mas que contexto de ideias que os envolvem motivaram essas leituras resistentes?

Em Nogueira, podemos constatar que aquilo que provoca esse rechaço é o teor individualista e anarquista de Nietzsche, pois ao longo do seu artigo, ele compara o filósofo a outros conhecidos por seu caráter anarquista como o americano Abraham Tucker e o alemão Max Stirner., combatendo essas correntes de pensamento. Nesse sentido, o brasileiro interpretou Nietzsche como um pensador individualista que, através da criação dos super-homens defendeu o extremo egoísmo, influenciando muitos jovens impulsivos, orgulhosos e arrogantes. O militar considerava o filósofo alemão, portanto, um inimigo do Socialismo e que, embora mascarasse o Individualismo com um rótulo mais pomposo para tentar estabelecê-lo na sociedade moderna, em síntese, fazia apologia a um egoísmo primitivo e grosseiro do homem. Além disso, essa filosofia individualista seria oposta à de Cristo tendo em vista que seu objetivo não seria "nem o Divino nem o Humano, nem o Verdadeiro nem o Bem, nem o Direito nem o Livre, mas tão somente o Meu, o único Eu".

Para rastrear mais a fundo de Nogueira, investigamos dois outros artigos de sua autoria. Suas ideias aparecem explicitamente em "Despedida" e em "Um livro" de 1908 e 1910 respectivamente. No primeiro, o escritor comunicou ao público sua saída do jornal, em 9 de janeiro de 1910, agradecendo o auxílio em "pugnar pelo Bem, pelo Direito, pela regeneração dos costumes e pelo bem-estar e interesses de nossa terra, sempre e ingratamente esquecidos" (NOGUEIRA, 1910: 2). No segundo artigo, aparece suas definições sobre a Liberdade e a Licenciosidade. A primeira, diferentemente da segunda, não significava a anulação dos deveres morais e sociais porque "sermos livres não quer dizer fazer tudo que nos aprouver". Segundo o texto, "a Liberdade como tudo mais tem seu limite, tem direitos e deveres que são precisos acatar e cumprir pois do contrário enveredaríamos pelo lado da estrada escabrosa da Licenciosidade e da anarquia (NOGUEIRA, 1908: 2)" Apesar de serem escassos os artigos assinados por Nogueira, seu pensamento pode ser conhecido também através dos textos de autores publicados nas páginas de A Razão. Como redator gerente, Nogueira participava da seleção dos autores e textos publicados diariamente e isso nos oferece um importante 
indício de suas afiliações filosóficas. Na primeira página, onde costumavam aparecer textos de caráter filosófico figuram autores, no ano de 1909, como Silvio Romero (14 de março de1909, edição 11) e Tobias Barreto (5 de setembro de 1909, edição 35). ${ }^{5}$ Ambos pensadores sergipanos pertenciam à geração de 1870 da Escola de Direito do Recife, que, embora não tivesse uma unidade de pensamento e apresentasse mudanças de perspectiva filosófica ao longo de sua constituição, se caracterizou, num primeiro momento, pela recepção do positivismo comtista, monismo naturalista de Haeckel e evolucionismo de Darwin na área jurídica. Esse grupo de juristas formados em Recife, na segunda metade do século XIX, atuou em prol da constituição de um Direito Científico, aliado à biologia evolutiva e à antropologia criminal, e à sociologia, em nome da civilização, progresso e da nação (SCHWARCZ, 1993: 196). ${ }^{6}$ Além disso, esses intelectuais são considerados os precursores do pensamento sociológico no Brasil ao estabelecer uma tentativa de diálogo com a sociologia para a afirmação do Direito como prática científica. Tobias Barreto, embora tenha sido grande leitor de Comte, compreendia que o homem era produto de um processo cultural e não de um produto natural como preconizava as ideias positivistas (PAIM, 1995: 29-30). Se analisarmos os artigos de Romero e Barreto, publicados no jornal, esses ideais estão presentes na exaltação da República, dos valores coletivos nacionais, da ordem social e do desenvolvimento histórico do caráter povo brasileiro. ${ }^{7}$

As ideias irracionalistas, decadentistas, individualistas e anticristãs de Nietzsche, portanto, se mostravam ameaçadoras à noção de progresso, de ordenação social e de evolução nacional compartilhadas pelo jornal, motivando em grande medida, a leitura resistente realizada por José Nogueira. Podemos constatar que sua defesa do Socialismo - entendido por ele como o contrário de Individualismo, não como contrário de Capitalismo - é uma afirmação da necessidade de pensar mundo social desde uma perspectiva sociológica e coletiva, adquirida durante o contato com intelectuais da faculdade de Direito do Recife. Esse aspecto se revelou um fator importante para que os

\footnotetext{
5 Tobias Barreto em edição de 14 de março de 1909 é chamado de "saudoso e imortal filósofo sergipano".

${ }^{6}$ Essas correntes de pensamento, no entanto, foram recebidas em um tom crítico, no qual se recusava o "dogmatismo positivista". A mestiçagem, ao contrário do que apregoavam grande parte das teorias evolucionistas europeias, era vista por Silvio Romero como algo possível e uma realidade que melhor seria aceita-la (SCHWARCZ, 2006: 48). A ideia de se pensar o determinismo biológico no campo social também foi questionada por Barreto.

7 Apesar de estabelecerem uma ciência jurídica cientificista, são valorizados tanto por Silvio Romero como por Tobias Barreto, aspectos do cristianismo e virtudes de Jesus, como aquele que tinha aptidão para o martírio, disposição do sacrifício. Assim, de certa maneira, não havia uma total ruptura com a religião por parte dos intelectuais sergipanos.
} 
aspectos individualistas, anárquicos e licenciosos da filosofia nietzschiana, fosse rechaçada pelo militar sergipano ${ }^{8}$.

Por outro lado, para Penteado, a filosofia de Nietzsche representaria a lógica cruel da natureza, que desconhece a caridade, os valores altruísticos, na qual os fracos não teriam direito à vida. Ela seria a antítese da lógica dos homens, cuja razão prevalece sobre a força e a inteligência sobre o coração. A crueldade e a perversidade definiriam o pensamento nietzschiano já que, semelhante à natureza atroz, seria indiferente ao sofrimento dos indivíduos mais débeis. Dentro do homem, as ideias de Nietzsche representariam a voz do coração, na medida em que ele se opõe a inteligência sendo até mais forte que a mesma. Penteado combate esse aspecto irracionalista do pensador alemão que é visto como uma ameaça à inteligência do homem e suas faculdades.

Essa leitura resistente do jornalista paulista se explica, em grande medida, em função de enxergar as ideias nietzschianas como análogas às darwinistas, um fenômeno comum à recepção brasileira do pensador alemão nesse período. O intelectual Alberto Torres associou Nietzsche a "certas filiações políticas e sociais do darwinismo", pois acreditava que ambos chegam "à mesma conclusão: a afirmação da superioridade, irredutível, de certas raças e certos povos (TORRES, 1914: 47)” Para Almachio Diniz, “a moral de NIETZSCHE, a moral de combate, é a verdadeira moral científica, tal como se a pode deduzir, com mais ou menos rigor e moderação, da teoria de DARWIN, sobre a struggle for life. (DINIZ, 1909: 37-59)".

Essas e outras considerações sobre o filósofo demonstram que seus textos muitas vezes foram lidos no Brasil, nesse momento, como um teórico darwinista ou socialdarwinista. Embora Penteado não haja realizado referência direta a Darwin, pode ser constatado em seu pensamento a crítica à ideia de aplicação das leis da natureza à "lógica dos homens", e um claro combate à corrente do darwinismo social. Nesse sentido, a rejeição do filósofo alemão ocorreu, em certa medida, no bojo da rejeição das ideias naturalista inglês e sua adoção como forma de compreensão do funcionamento do mundo social. Essa recusa ocorreu primeiro, porque a ideia de seleção natural, foi entendida, sobretudo, como uma explicação natural para a diversidade do mundo

\footnotetext{
${ }^{8}$ Podemos encontrar outras manifestações de rejeição a esse teor individualista e egoísta da filosofia de Nietzsche desde o fim do século XIX em jornais brasileiros. Para tanto, conferir artigo de Júlio Erasmo de 1893 publicado no jornal A Gazeta de Notícias, no qual o autor afirma que "Segundo Nietzsche, não existe uma moral geral humana, porém sim duas, cada qual para a raça a que é destinada. A obrigação única do nobre, constituído assim pela natureza, é desenvolver os seus instintos, de que é coroamento o egoísmo, isto é, a fé inabalável de que ele nasceu para que os mais se subordinassem e se sacrificassem ao seu bem-estar e à expansão das suas qualidades excepcionais.
} 
orgânico e, em princípio, prescindia da ideia de Deus (GUALTIERI em DOMINGUES, 2003: 80). Ademais, a concepção de seleção, foi interpretada "como um mecanismo que não dava oportunidade aos seres vivos de exercerem um papel ativo no exercício do curso da evolução, e tampouco de reagir as mudanças do ambiente já que as formas não-adaptativas seriam eliminadas", mostrando-se, portanto, "inconciliável com qualquer ação divina e conflitante com a visão teleológica do mundo". Consequentemente, noções tão em voga no século XIX, como progresso e aperfeiçoamento, se enfraqueciam nas explicações sobre as transformações do mundo vivo e de sua história (GUALTIERI em DOMINGUES, 2003: 81). Das formulações darwinistas, a seleção seria a mais rejeitada, não somente pelo público leigo, mas também pelos filósofos, teólogos e os próprios biólogos e cientistas em geral. ${ }^{9}$

O discurso antidarwinista esteve presente na imprensa católica brasileira de maneira marcante principalmente na segunda metade do século XIX e era sustentado "a partir da negação da origem comum entre os seres vivos e da imutabilidade das características físicas das espécies (SOUZA, 2020)”. No próprio periódico que escrevia Penteado, encontramos um artigo em 1901 que alertam sobre os perigos do darwinismo, associando um assassinato e um suicídio à influência das obras do naturalista inglês. $\mathrm{O}$ Jornal Pequeno, embora não possuísse uma orientação católica, possuía em seu interior diversos anúncios de cerimonias da Igreja e notícias relacionadas ao catolicismo. Inclusive na mesma página que foi publicado o texto de Penteado, no qual Nietzsche é citado, podemos encontrar um anúncio sobre uma celebração religiosa católica. ${ }^{10}$ Apesar da presença católica no periódico, a crítica à Nietzsche de Ernesto Penteado, pode ser explicada mais em função de sua filiação ao Espiritismo. Em 1904, foi fundada por ele a Sociedade de Estudos e Propaganda do Espiritualismo Científico-Filosófico (NOGUEIRA, 2016: 117). No mesmo ano, o jornalista também fundou em Taubaté, estado de São Paulo, O Alvião, Revista científico-filosófica do espiritismo (DIAS, 2006). Além disso, o intelectual espírita viajou diversas viagens pelo Brasil com o intuito de divulgar essa sociedade. Seu ataque ao pensador alemão se deu

\footnotetext{
${ }^{9}$ Como assinala Domingues e Sá, os trabalhos de antropologia e arqueologia realizados em sambaquis ou sobre os índios botocudos foram um meio e também um fórum de debate para a afirmação ou rejeição da teoria da evolução das espécies no país (DOMINGUES e SÁ, 2003: 15-16).

10 Após duas propagandas de bebida, há um anúncio também na primeira pagina, da Grande Festa no Seminário Arquiepiscopal de Olinda em ocasião da assunção da Santa Virgem, no dia 15 de agosto de 1911.
} 
principalmente porque sua lógica cruel se assemelharia à lógica natural uma vez que desconhece a caridade, um dos valores fundamentais do pensamento espírita.

A partir do que foi analisado, em ambos autores se notam uma leitura desviacionista, no qual Nietzsche é interpretado segundo a cultura própria do consumidor. Ao assimilar a mensagem do autor, esses leitores também resistiram a ela, de maneira mais ou menos consciente. Em outras palavras, os leitores se recusaram, em menor ou maior grau de consciência, a ler da maneira como o próprio autor queria ser lido. Por "mais consciente" entendemos a recusa voluntária da mensagem que o texto carrega, isto é, uma resistência ao "propósito inicial" do autor do texto. Por resistência "menos consciente" entendemos uma leitura que resistiu involuntariamente à mensagem do texto, ou seja, modificou o objeto (texto) de maneira inconsciente, revelando nesse processo um desvio entre a intenção do produtor da mensagem e de seu consumidor. Esse consumo ou assimilação, segundo De Certeau, em vez de ser tomado como um processo no qual aquele que consome ou assimila torna-se parecido àquilo que se absorve, pode ser considerado como um fenômeno no qual o consumidor (leitor) faz do produto que consome (texto) algo semelhante a ele, ou um produto seu, apropriando-se ou reapropriando-se dele.

Os processos de apropriação dos leitores analisados revelam uma resistência ao texto mais ou/e menos consciente. Nogueira, num nível mais inconsciente, leu o filósofo alemão, por exemplo, como porta-voz de um egoísmo grosseiro. Scarlett Marton, uma das maiores intérpretes de Nietzsche do Brasil, sustenta que o pensador redefine a noção de egoísmo, através de uma recusa da concepção moderna de sujeito (MARTON, 2018: 899). Esse egoísmo, segundo a filósofa, consistiria no trabalho de tornar-se o que é, à concepção de amor de si, uma procura de si, um egoísmo sem ego, no qual "não há lugar para um sujeito que se mantém sempre o mesmo em sua individualidade" tendo pouca aproximação com um sentimento individualista arrogante, atribuído por Nogueira. Desse modo, segundo a cânone do pensamento nietzschiano, o militar teria feito uma apropriação da noção de egoísmo proposta pelo filósofo alemão, o que para De Certeau pode ser considerado uma leitura de desvio ${ }^{11}$. Num nível mais consciente, o sergipano rejeitou as ideias de Nietzsche, na medida em que essas representavam uma ameaça ao Socialismo e à filosofia de Cristo, pois pregavam a desigualdade como algo

\footnotetext{
11 Gostariamos de chamar atenção para o fato de que em vez de trabalhar com a ideia de "mal entendido" que carrega um sentido negativo, pois atribui uma incapacidade de compreensão por parte leitor , De Certeau utiliza os termos "apropriação", "produção silenciosa", "invenções", "arte", "desvio" e "consumo".
} 
inerente ao ser humano. Essas ideias aristocráticas, para Nogueira, proclamavam que "alguns nasceram para reis e outros para escravos" e defendiam o egoísmo e o Individualismo, através da noção de super-homem.

Penteado, por sua vez, aproximou a filosofia nietzschiana ao darwinismo e a ideia de uma seleção natural, em voga nesse momento, em sua reflexão acerca da relação entre fortes e fracos, tendo como critério a força física. Como foi sugerido em seu artigo, o pensamento nietzscheano propõe que se negue um pedaço de pão a um senhor octogenário faminto, uma vez que não deveríamos ter compaixão com indivíduos mais velhos. Ao efetuar uma leitura que considera Nietzsche um defensor da aplicação das leis naturais à sociedade, o jornalista paulista apresentou uma prática desviante em relação aos seus "verdadeiros intérpretes." ${ }^{12}$ Esses últimos afirmam que o filósofo nunca teve como critério a força física como definidor de indivíduos fortes e fracos. A luta, pelo contrário, seria o modo pelo qual os fracos prevalecem sobre os fortes, contrariando assim Darwin (DELEUZE, 1976: 40) ${ }^{13}$. No entanto, o ponto central das objeções nietzschianas à luta pela existência, seleção natural, seleção sexual e desenvolvimento da moral têm o seu eixo numa divergência entre Nietzsche e Darwin a respeito da concepção da vida. Como aponta Wilson Frezatti Jr., "enquanto para Darwin o impulso básico vital é a conservação, Nietzsche apresenta-nos a vida como um movimento de autossuperação contínua (2014: 14)"14. Desse modo, "as minúsculas partes de um organismo vivo, não lutam por prazer ou por um objetivo que seria, por exemplo, a auto conservação ou subsistência, como pensa Darwin, mas por 'um plus de poder' (MARTON, 2017: 34)" A leitura consolidada pelos “intérpretes oficiais" sobre a dualidade entre fortes e fracos no pensamento nietzschiano, grosso modo, diz respeito às forças ativas e reativas, ou seja, as que agem de maneira ativa sobre a vida e as que agem de forma reativa. De forma mais consciente, Penteado resistiu às ideias nietzschianas por atribuir aos instintos e às emoções um valor preponderante em relação à inteligência, o que, para ele, seria um grande perigo, tendo em vista que o coração pode confundir o homem e provocar sua desgraça.

\footnotetext{
12 Fazemos referência ao termo utilizado por De Certeau que se refere a "um grupo privilegiado de intérpretes oficiais que entregam passaportes, ao transformar sua leitura em uma literalidade ortodoxa que reduz as outras leituras (igualmente legítimas)" (DE CERTEAU, 2000: 184)

13 "Não é ao menos forte que Nietzsche chama de fraco ou escravo, mas àquele que, qualquer que seja sua força, está separado do que pode" (Deleuze, 1976, p.50). Desse modo, o forte seria aquele ativo e o fraco o reativo.

${ }^{14}$ Essa distinção entre o pensamento do filósofo alemão e do biólogo inglês, e as críticas que o primeiro remete ao segundo são exploradas por Wilson Frezatti Jr. em seu livro Nietzsche contra Darwin. Esse trabalho de Frezatti Jr. teve a orientação de Scarlett Marton.
} 
Mediante essas conclusões, podemos afirmar que Penteado e Nogueira resistiram ao texto de Nietzsche, pois representava ideais individualistas, cruéis, irracionais, que se opunham aos valores altruístas, cristãos, caridosos e socialistas defendido pelos leitores brasileiros. É interessante chamar atenção para o fato de que Nietzsche nesse momento foi acolhido por grande parte dos intelectuais brasileiros ligados ao simbolismo e ao pré-modernismo. Entre as décadas de 1890 e 1920, escritores como João Ribeiro, José Veríssimo, Nestor Victor, Augusto dos Anjos, Monteiro Lobato e Graça Aranha fizeram referência ao filósofo, destacando aspectos "positivos" de sua filosofia e se apropriando dela para escrever suas obras (LOMEU, 2015). Muitos deles atribuíram ao individualismo nietzschiano um valor a ser incorporado. Toda essa difusão brasileira do pensador se deve, em grande medida, à moda Nietzsche na França, ocorrida entre 1890-1914 (FREZATTI, 2012: 60). Essa moda se refere ao grande sucesso que teve o pensamento nietzschiano entre os intelectuais franceses. Portanto, o Brasil, nesse período, em função da forte presença da cultura intelectual francesa e da circulação de obras de autores franceses, teve uma importante difusão de Nietzsche. No caso de Penteado e Nogueira, no entanto, essa difusão encontrou uma importante resistência.

Essas formas de ler Nietzsche podem ser vistas como modificadoras do seu objeto, pois esquivam a lei de cada texto em particular. Essas leituras também revelam um autodidatismo e um ecletismo presentes na interpretação dos textos filosóficos nesse momento, justamente porque no Brasil não havia se formado um campo filosófico institucional que legitimasse ou autorizasse certas leituras de Nietzsche. Mediante isso, pudemos perceber uma resistência de duas formas: na forma como os textos nietzschianos foram lidos (foram interpretados e apropriados implicitamente), e na forma como eles foram rejeitados (ao não concordarem explicitamente com sua mensagem)

A escolha dos leitores não vinculados aos círculos consagrados intelectuais segue a crítica feita por De Certeau que indica que "desgraçadamente a abundante literatura consagrada à leitura [...] trata de experiências eruditas" e lança a seguinte pergunta provocativa: "esta atividade leitora está reservada ao crítico literário (sempre privilegiado pelos estudos sobre a leitura), isto é, outra vez a uma categoria de intelectuais, ou pode se estender a todo consumo cultural? Segundo o intelectual francês, as manifestações de liberdade do leitor estão proibidas aos alunos e ao público em geral, mas podem ser toleradas entre os intelectuais (tem que ser Barthes para 
permiti-lo). O próprio Barthes critica a concepção de que se deve "dar um Autor a um texto", impondo a esse texto um mecanismo de segurança e dotando-o de um significado último, um segredo. De acordo com essa perspectiva, o Crítico seria o único leitor responsável por descobrir o Autor sob a obra. Dessa maneira, escolhemos examinar esse campo inexplorado apontado pelas novas propostas da história da leitura, aquele que traz à luz leituras esquecidas e silenciadas, porém igualmente legítimas, de textos que em certa medida são reservados aos críticos ou eruditos.

\section{Fontes}

Nogueira, José. Aparando Golpes, Jornal A Razão, 1909, Edição 19, p.1 e 2.

Penteado, Ernesto. A lógica dos Homens, Pequeno Jornal, 1911, Edição 180, p.1.

\section{Referências bibliográficas}

BARTHES, Roland (2004). A morte do autor em: O Rumor da Língua. São Paulo: Martins Fontes.

BELLEI, Sérgio Luiz Prado (2014). A morte do Autor: um retorno à cena do crime, Ver. Cria e Crit., São Paulo, n.12, p.161-171, jun.

CARRERA, Julián (2019). Microresistencia e infrapolítica: Debates actuales sobre resistencia cotidiana de los dominados, Seminario - Programa, UNLP, in: http://www.memoria.fahce.unlp.edu.ar/programas/pp.11563/pp.11563.pdf

CHACON, Vamireh (1977). História das Ideias Sociológicas no Brasil. São Paulo, Edusp/Grijalbo.

CHARTIER, Roger (2001) Cultura Escrita, Literatura e História. Editora Artmed, Porto Alegre.

(2002). História Cultural: Entre práticas e representações, Difel, Algés,

Deleuze, Gilles (1976). Nietzsche e a filosofia, Editora Rio, Rio de Janeiro,

DE CERTEAU, Michel (2000). La invención de lo cotidiano: 1. Artes de Hacer, Universidad Iberoamericana, Mexico,

DIAS, José Robeto de Lima (2006). A Evolução (1892-1893): uma amostra dos fatores constituintes do sistema literário espírita, Dissertação de Mestrado, Universidade Federal do Rio Grande,

DOMINGUES, Heloisa Maria Bertol (Org.) (2003). A Recepção do Darwinismo no Brasil. I Organizado por Heloisa Maria Bertol Domingues et al.- Rio de Janeiro: Editora Fiocruz,

FREZATTI JR., Wilson Antonio (2012). A recepção de Nietzsche na França: da Revue philosophique de la France et de 1' Étranger ao período entreguerras, cadernos Nietzsche 30 Paulo: Edições Loyola.

(2014). Nietzsche contra Darwin. 2 ed. amp. e rev. São

LOMEU Teixeira Barroso, Antonio Vinícius (2015). Um Nietzsche à brasileira: a recepção do pensamento nietzscheano no Brasil 1890-1940, Dissertação de Mestrado, UFRRJ,

MARTON, Scarlett (2018). "Fiz de minha vontade de saúde, de vida, minha filosofia...". Nietzsche e o problema da medicina em "Ecce Homo", KRITERION, Belo Horizonte, $\mathrm{n}^{\circ} 141$, p. 891-903, Dez.l 
(2017) Nietzsche y "la nueva concepción del mundo" 1a ed. Córdoba: Brujas,

NIETZSCHE, Friedrich (2007). O Anticristo, Maldição ao Cristianismo. Tradução, notas e posfácio de Paulo César de Souza. São Paulo, Companhia das Letras,

NOGUEIRA, Fausto Henrique (2006). Os espíritos assombram a metrópole: sociabilidades espíritas em São Paulo na Primeira República, Tese de Doutorado, Universidade de São Paulo,

PAIM, Antônio (1981). A filosofia da Escola do Recife. $2^{\mathrm{a}}$ ed. São Paulo: Editora Convívio,

PENTEADO, Ernesto (1904). Marchemos! Ligeiras considerações sobre a vida dos animais e a dos homens precedidas de um estudo psíquico-biográfico do autor, feito por N, Viana. São Paulo Typografia Andrade e Mello,

SANTOS, Ana Barbosa (2017). Civilização, modernidade e educação nas páginas do jornal A Razão (1898-1923), São Cristóvão (SE), Universidade Federal de Sergipe, Tese de doutorado.

SALANSKIS, Emmanuel (2013). Sobre o eugenismo e sua justificação maquiaveliana em Nietzsche, cadernos Nietzsche 32.

SCHWARCZ, Lilia Moritz (1993). O espetáculo das raças: cientistas, instituições e questão racial no Brasil (1870-1930). São Paulo: Companhia das Letras.

(2006) Quando a Desigualdade é Diferença: Reflexões sobre Antropologia Criminal e Mestiçagem na Obra de Nina Rodrigues, Gazeta Médica da Bahia;76(Suplemento 2):47-53.

SOUZA, Raick (2020). O anti-darwinismo católico na imprensa brasileira durante a segunda metade do século XIX, Rev. Hist. UEG-Morrinhos, v.9, n.1, e-912012, jan./jun.

Artigo recebido em 4 de março de 2021.

Aprovado em 25 de maio de 2021.

DOI: 10.12957/intellectus.2021.54767 